\title{
La casa
}

\section{Paco Roca}

Astiberri, 2015

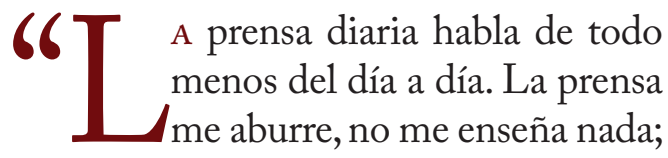
lo que cuenta no me concierne, no me interroga y ya no responde a las preguntas que formulo o que querría formular. Lo que realmente ocurre, lo que vivimos, lo demás, todo lo demás, ¿dónde está? Lo que ocurre cada día y vuelve cada día, lo trivial, lo cotidiano, lo evidente, lo común, lo ordinario, lo infraordinario, el ruido de fondo, lo habitual, ¿cómo dar cuenta de ello, cómo interrogarlo, cómo describirlo?”. ${ }^{1}$ Lo escribió Georges Perec

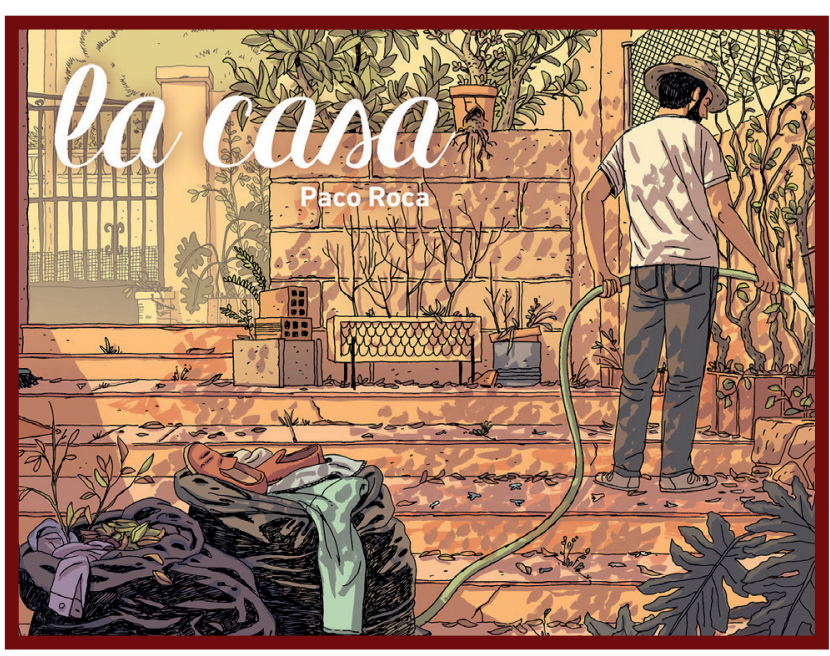
en el texto que encabezaba a modo de manifiesto Lo infraordinario (1989), y para mí que Paco Roca ha debido de hacerse preguntas parecidas a la hora de resolver el que por ahora es su último trabajo.

La casa (2015), publicada hace menos de un mes cuando escribo estas líneas, me parece la clásica "obra difícil" que afronta un autor después de haber llegado a una cumbre artística. Los surcos del azar (2013) lo era, un trabajo de madurez y envergadura en el que Roca entrelazaba pasado y presente para construir una memoria que, aunque acudiera a elementos ficticios para enfatizar y dar coherencia a la narración, estaba firmemente basada en una realidad histórica que, no por casualidad, sigue siendo poco conocida en España: la historia de La Nueve, la primera compañía militar que entró en París el día de la Liberación, compuesta en su mayoría por republicanos españoles, exiliados que lucharon en diversos frentes aliados de la II Guerra Mundial. La recepción de crítica y público de la obra, con numerosos galardones, generosas ventas y varias ediciones internacionales, sancionó su importancia, en términos artísticos y de relevancia social. En mi opinión, Los surcos del azar no fue solo uno de los mejores cómics de su año en términos internacionales, también aportaba un nuevo y trascendente capítulo en la construcción de la memoria histórica española, una tarea ardua que aún hoy se realiza en nuestro país a pesar de incomprensiones varias, silencios o reproches tópicos cómo "¿para qué recordar el pasado?"

1 Georges Perec, Lo infraordinario, Traducción de Mercedes Cebrián, Madrid, Impedimenta, 2008, pp. $22-23$. 
A esa pregunta absurda, políticamente interesada o ignorante dependiendo de quien la formule, se puede responder de varias formas. Paco Roca (Valencia, 1969) parece responderla como mejor sabe hacerlo un creador: con una nueva obra. La casa trata justamente de la necesidad de recordar, porque la identidad, sea individual o colectiva, está hecha de memoria. Y la memoria hay que sembrarla, cultivarla, regarla como el huerto que aparece en este libro. La memoria es, también, el gran tema personal de Paco Roca. Ya le había preocupado en su célebre Arrugas (2007), ahí desde un punto de vista individual y cotidiano; al fin y al cabo, el protagonista era un anciano enfermo de Alzheimer, inspirado en el padre de un buen amigo pero también en la vejez de sus propios progenitores. También abordó tangencialmente la memoria colectiva de la posguerra española al hilo de la memoria profesional del tebeo en El invierno del dibujante (2010), donde el pasado republicano del editor y varios dibujantes de la barcelonesa Bruguera se convertía en un elemento destacado de la narración. La memoria del exilio tras la Guerra Civil la había tocado en El faro (2004), aunque en clave de fábula, y más directamente en El ángel de la retirada (2010, con guión de Serguei Dounovetz), una aproximación más documental al recuerdo de los campos de refugiados españoles en Francia.

Como decía, afrontar el siguiente trabajo después de una obra de la dimensión de Los surcos del azar era empresa delicada. En esta ocasión el objeto de la memoria es el padre muerto, y alrededor de él, la familia, temas mayores de la literatura. Frente a la carga histórica y colectiva que había en Los surcos del azar, La casa es una memoria íntima y cotidiana que parece responder al mismo tipo de preguntas que se hacía Perec. En efecto, lo "infraordinario" habita en estas viñetas, con todo el peso del tiempo y la vida vivida asociado a ello:

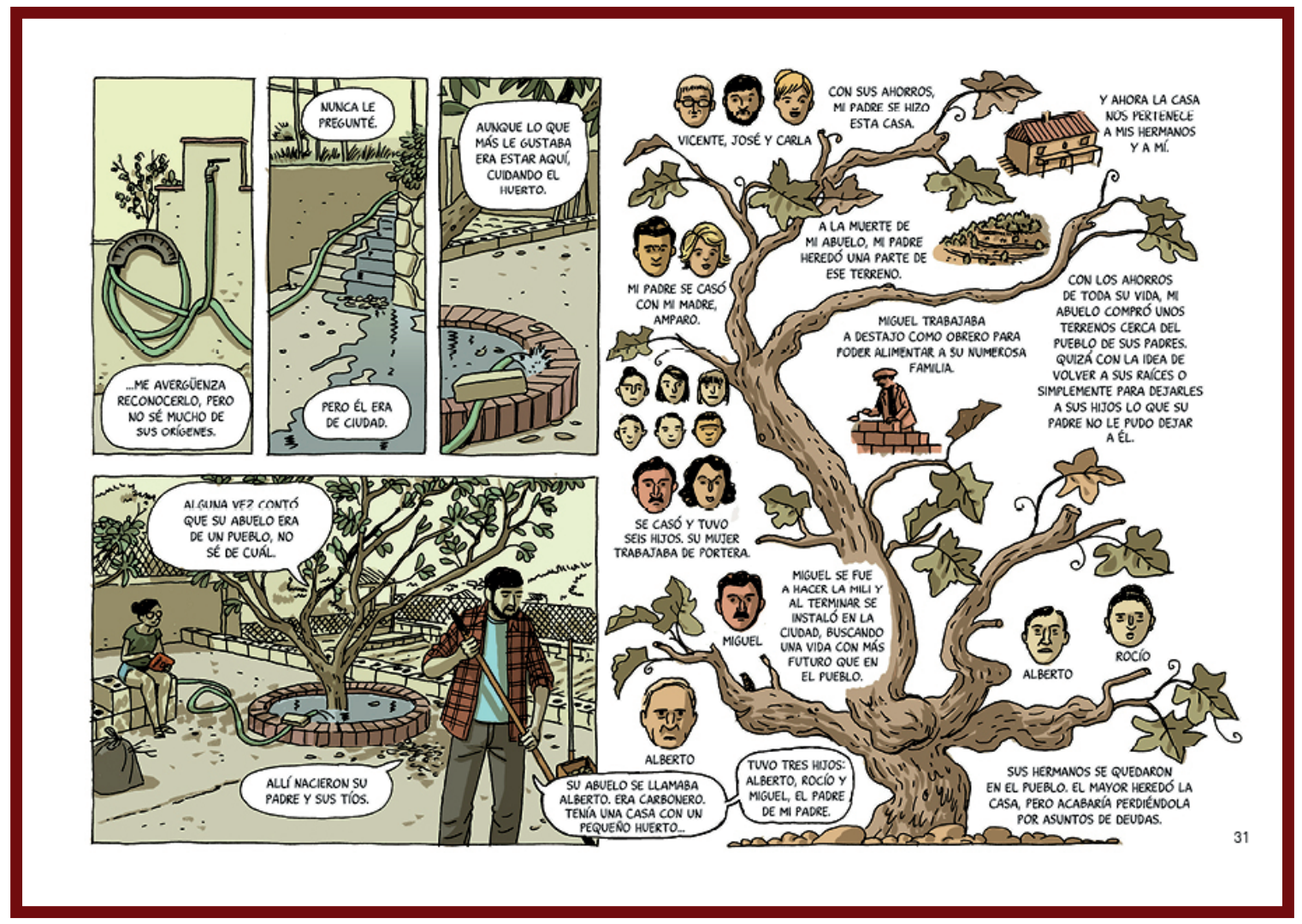




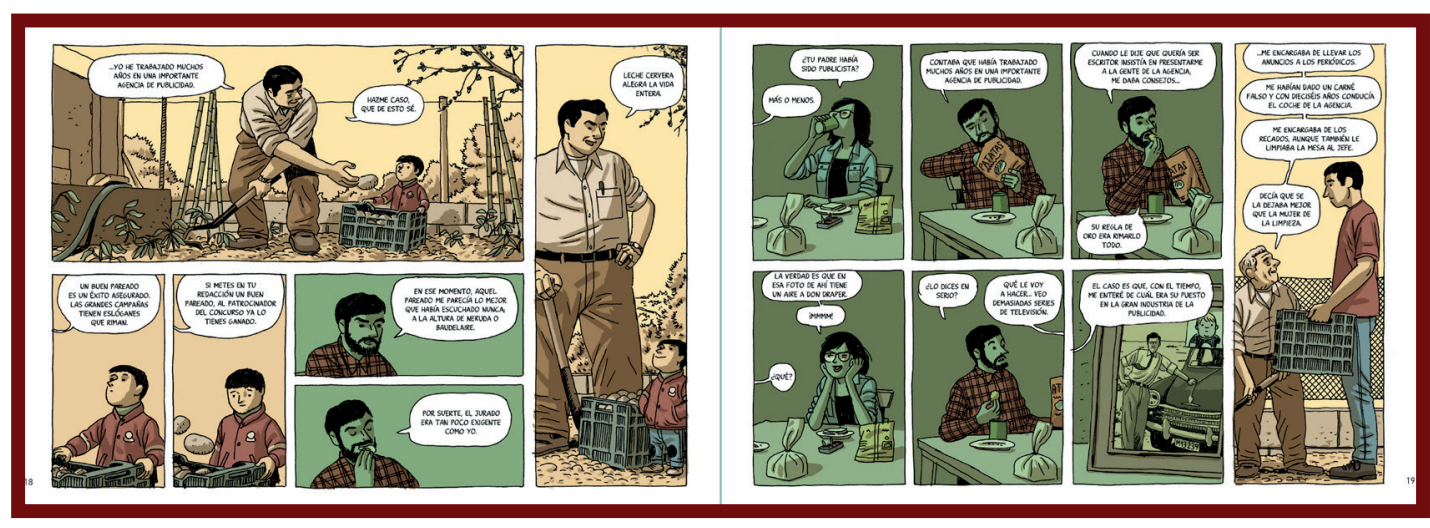

una pequeña casa de campo, segunda residencia edificada por el padre con la ayuda de unos hijos no siempre dóciles, una piscina ahora vacía y llena de fango, antaño construida por esas manos familiares, las hojas muertas por barrer, la persiana sacada de su guía por el viento pero "no rota", el muro casero firmado en el cemento fresco por sus albañiles aficionados, el secador del pelo que se enreda y cae presagiando tal vez alguna "ruptura", la cisterna que gotea, la pérgola para la parra, las comidas familiares, incluso las esperas en la sala del hospital, ya al final del trayecto. "De lo que se trata es de interrogar al ladrillo, al cemento, al vidrio, a nuestros modales en la mesa, a nuestros utensilios, a nuestras herramientas, a nuestras agendas, a nuestros ritmos", escribía Perec. "Interrogar a lo que parecería habernos dejado de sorprender para siempre. Vivimos, por supuesto, respiramos, por supuesto, caminamos, abrimos puertas, bajamos escaleras, nos sentamos a la mesa para comer, nos acostamos en una cama para dormir. ¿Cómo? ¿Dónde? ¿Cuándo? ¿Por qué?”2

La casa, aunque no tenga el trabajo de documentación histórica que exigió Los surcos del azar, me parece un libro más difícil de realizar en términos creativos, porque aquí no existe el "tema histórico importante" ni la "peripecia aventurera" ("hazañas bélicas") para captar la atención del lector y conducirle por la narración. El tema de La casa tiene menos asideros narrativos, el "argumento" que hay que amasar para darle forma es una vida corriente, la de un padre crecido en la posguerra española y, alrededor de él, la de sus hijos, la generación a la que pertenece el autor. Por eso entre otras razones (enseguida apuntaré otras) una obra como La casa exige una mayor batería de recursos artísticos y más bagaje como autor, algo que el lector atento puede comprobar en cada una de sus páginas. Y Roca aplica con sabiduría todo lo que ha aprendido en sus cómics previos para seguir creciendo como artista y realizar una obra distinta pero al mismo nivel de excelencia que Los surcos del azar.

Me refiero por ejemplo a recursos formales que Roca había ido poniendo a punto en obras previas, como el uso de diferentes gamas cromáticas para distinguir estaciones y periodos temporales, probado en El invierno del dibujante y Los surcos del azar y ahora fundamental para las abundantes anacronías de La casa. En los diseños de página, Paco se ha ido moviendo desde la concepción clásica de tiras regulares y viñetas como ventanas invisibles a un "mundo completo" en el que transcurre la diégesis narrativa, un sistema hegemónico en el cómic tradicional de la segunda mitad del siglo xx según el modelo de influencia cinematográfica de Milton Caniff (así era básicamente toda la obra de Roca hasta El invierno del

2 Perec, Lo infraordinario, op. cit., p. 24. 


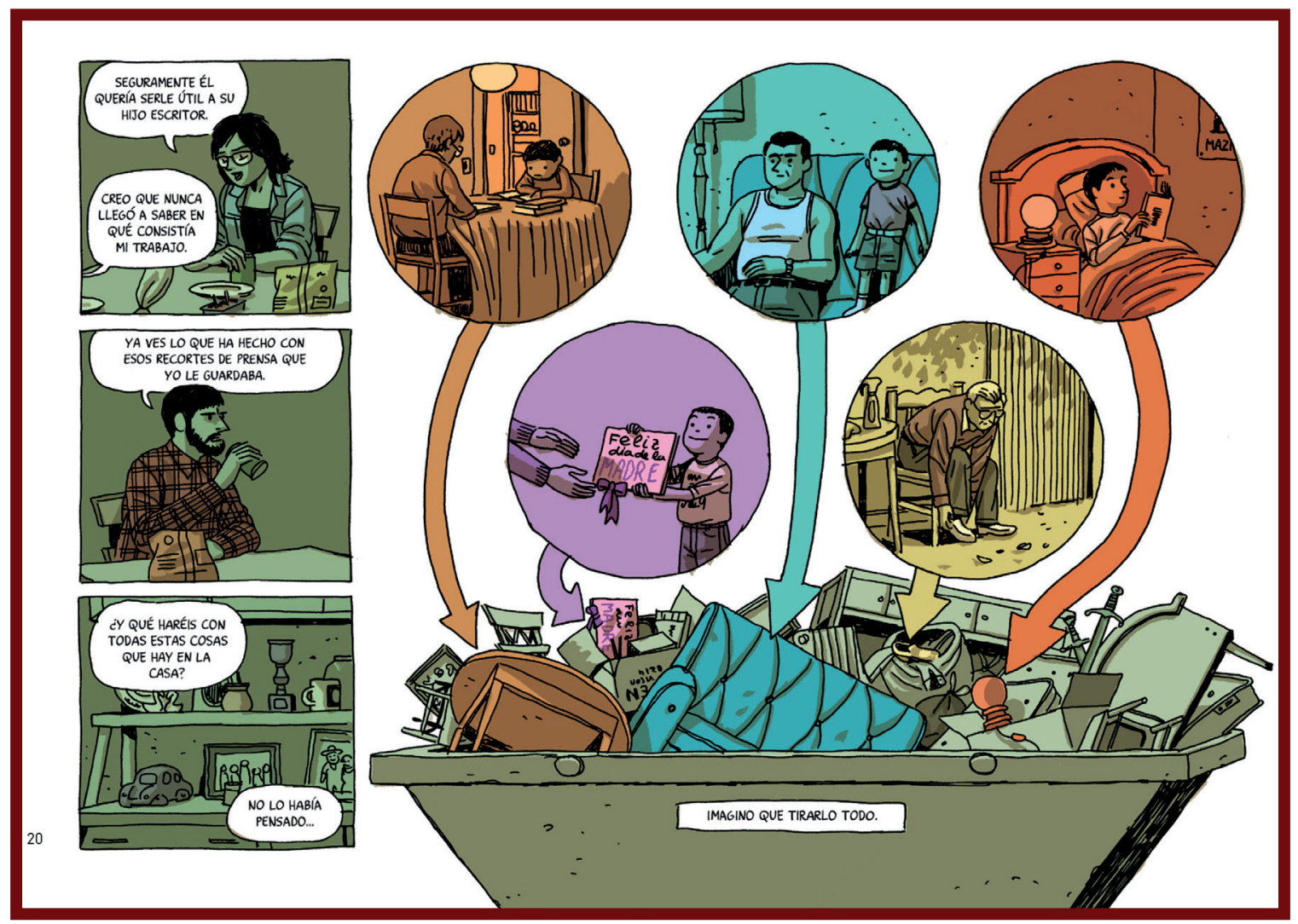

dibujante), a diseños complejos donde los artificios gráficos y los planos repetidos se hacen evidentes al lector y constituyen el núcleo narrativo de la página, inspirados por la lectura confesada de novelistas gráficos como Chris Ware o Seth. Puede decirse que La casa adopta un sistema sincrético entre esos dos modelos narrativos, el del cómic de aventuras derivado de la narración de continuidad del Hollywood clásico y el de la novela gráfica contemporánea que ha desarrollado el despliegue gráfico de ciertos historietistas de prensa de las primeras décadas del siglo xx.

Ahí están esas páginas diagramáticas de $L a$ casa, que Roca había experimentado previamente en su serie de prensa humorística — recopilada en Memorias de un hombre en pijama (2011) y Andanzas de un hombre en pijama (2014) — y en Los surcos del azar, que permiten contar las cosas con modos especificos del cómic además de economizar páginas, y que ahora se despliegan con una eficacia narrativa y emocional asombrosa: el árbol genealógico familiar (p. 31 de La casa), el conmovedor diagrama sobre los objetos y muebles viejos arrumbados en el contenedor, verdadero mapa temporal y sentimental (p. 20), las viñetas de diversas épocas asociadas a los anillos del tronco de un árbol plantado en la casa (p. 33), etcétera. Hay elementos simétricos enfrentados en la doble página con una sutileza memorable (pp. 18-19 y otras), por no hablar del modo en que Roca cambia la disposición de las calles de las viñetas en la retícula ortogonal de una misma página para jugar ambiguamente con el tiempo narrativo o el sentido de lectura. Ayuda a todo ello el formato apaisado del libro, un sistema horizontal que no solo se asocia al muro del patio interior que ocupa la portada y convierte a las viñetas en ladrillos de la "casa" que es el libro, sino que básicamente está pensado para permitir un diseño interior que resulta crucial en la obra. Gracias a él es posible 
"tocar el tiempo" en sus páginas, parafraseando a Jorge Carrión. ${ }^{3}$ El Tiempo con mayúsculas, que en efecto es el otro gran tema del libro, como indica Fernando Marías en el epílogo.

Pero, para capturar el tiempo, a Paco Roca no le basta intuir que la forma del cómic tiene un potencial específico para evocar el pasado y el presente en la misma página, incluso el futuro. $\mathrm{El}$ autor tiene además que inventar lenguaje, recursos visuales y textuales, formas y ritmos de escritura (aquí exclusivamente a través de los diálogos en bocadillos) para tratar temas hasta ahora escasamente abordados en el cómic. Decíamos antes que la memoria sobre el padre muerto y la familia son temas mayores que la literatura viene tratando desde hace mucho tiempo. El mismo Perec se planteó tematizar lo "infraordinario" en sus textos hace ya más de tres décadas. ¿Cuántos cómics han tratado hasta ahora, finales de 2015, esos temas de manera directa, sin acudir a clichés de aventuras y otros géneros tradicionales del cómic juvenil? Todos sabemos honestamente que son muy pocos, y menos aún parecidos a La casa. Por eso resulta sorprendente que aún haya algunas voces tan despistadas - entre ellas no faltan historietistas fracasados, por cierto - como para afirmar que la novela gráfica no está generando un lenguaje diferente a los cómics tradicionales, o que sus códigos visuales y comunicativos son los "mismos" solo porque ambos utilizan dibujos y viñetas. Ante semejante afirmación uno no puede evitar pensar que quien la dice no ha reflexionado demasiado, precisamente, sobre las cuestiones formales y temáticas sobre las que opina de manera tan frívola. No, La casa no es ni puede ser igual que un comic book de La Patrulla-X o Spiderman, y conste que les habla un fan de Spiderman y la Marvel de los sesenta y setenta. No se trata de una cuestión de calidad o de "elitismo", se trata de que son cómics que no hablan de las mismas cosas ni tampoco lo hacen con el mismo lenguaje, los mismos recursos

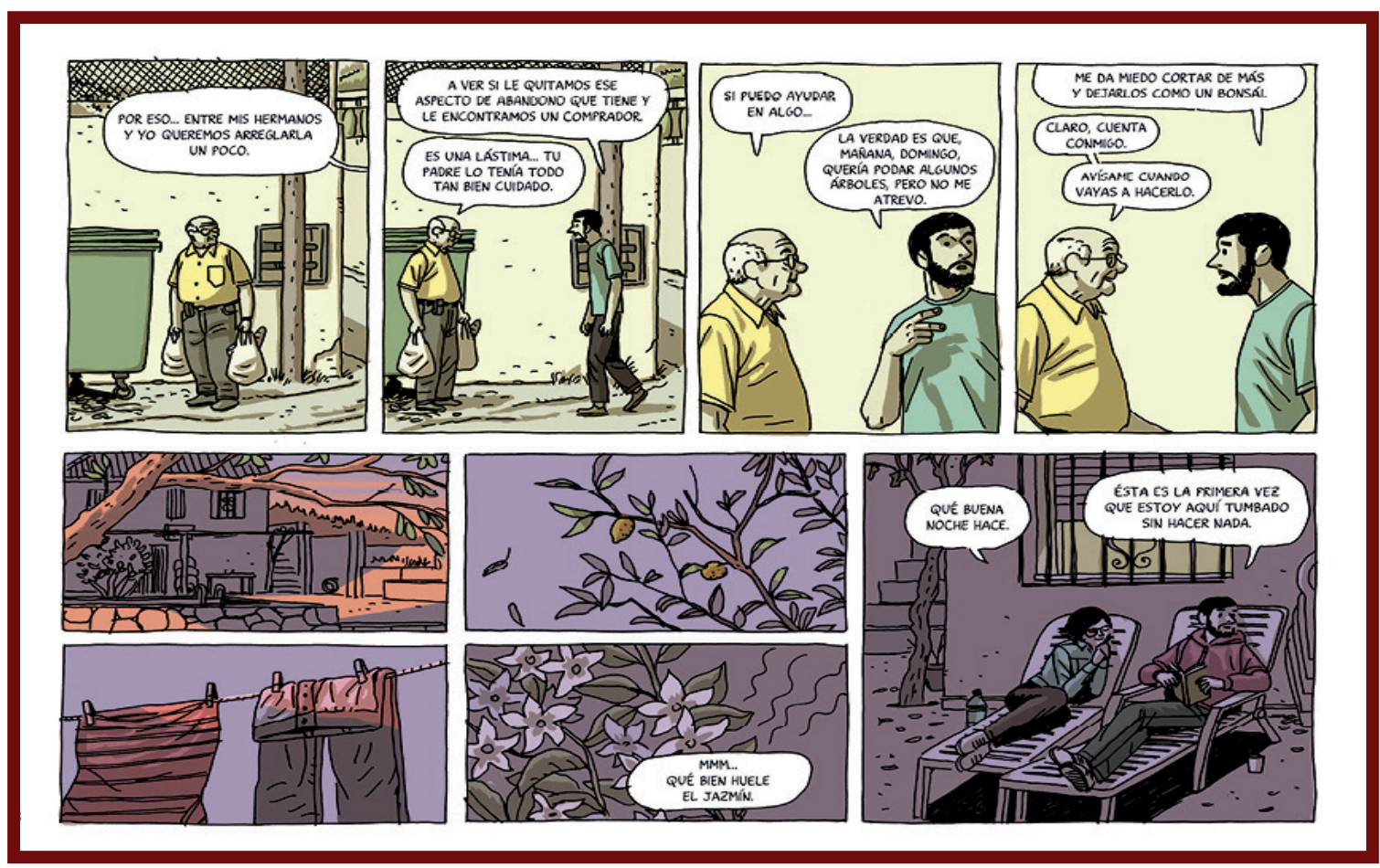

3 En su reseña de La Casa para Rockdelux (enero de 2016), a punto de llegar a kioscos cuando escribo estas líneas. 
formales, los mismos conceptos y modos de producción. Antes de seguir, dejémoslo claro que no cuesta nada: las novelas gráficas son cómics, por supuesto, solo que hablamos de una nueva tradición del cómic cuyos ascendentes directos apenas tienen cuarenta años. ${ }^{4}$

Cuando Paco Roca aborda una empresa como La casa, un cómic que trata sobre LA VIDA sin excusas de género (ni superpoderes ni galaxias lejanas, ni siquiera cuentos de autoayuda con moraleja reconfortante), tiene escasos modelos que seguir y por eso no tiene más remedio que tirar de todo su bagaje y talento para, digámoslo por última vez, inventar. Tiene a Chris Ware y unos pocos sospechosos habituales de la novela gráfica como referentes, poco más. El propio Ware, máximo referente actual de la novela gráfica sobre la realidad, entendida esta como la vida ordinaria y lo pequeño cotidiano, no ha parado de inventar recursos para poder tratar esos temas casi inéditos en el cómic. Temas básicamente para adultos, naturalmente, en un medio que hasta hace pocas décadas apenas producía cómics para adultos. El propio Ware tuvo escasos modelos a los que poder acudir: algunas páginas dominicales de viejos historietistas de prensa casi olvidados que él mismo se ha encargado de reivindicar (Frank King entre ellos), el magisterio de Art Spiegelman, una historieta de R. Crumb por allí ("A Short History of America", 1979), otra de Richard McGuire por allá ("Here", de 1989, tampoco por casualidad convertida ahora en un libro completo, Aqui, una novela gráfica de 300 páginas con la que La casa guarda más relación de la que pueda parecer, aunque McGuire y Roca hayan trabajado simultáneamente y por diferentes derroteros formales)... y pare usted de contar. El resto procede de esa gran cabeza que tiene Ware, donde parece caber todo el cómic posible o por venir.

Por si alguien se ha perdido, creo que Paco Roca empieza a resistir la comparación con esa liga de historietistas, y al buen entendedor pocas palabras le bastan. No se trata de decir quién es mejor o peor, pero sí de señalar niveles de excelencia. Si Roca viviese en Estados Unidos o Francia, no me cabe duda de que su libro estaría colocado a lo grande en un montón de países, a lo Alison Bechdel o Marjane Satrapi. Desde las provincias humildes del imperio resulta más difícil que el mundo te haga caso, aunque La casa tendrá en breve ediciones internacionales (Francia y Alemania). Un par de cuestiones más para ir terminando: el acierto de Roca al vincular los recuerdos familiares a los objetos y usarlos como tropo para crear una suerte de álbum de familia metonímico. El hombre crea objetos "a su imagen y semejanza", digamos, y de ahí la carga emocional asociada a esa cisterna que quedó por arreglar, la higuera que no termina de "tirar" pero que "algún" día dará higos, la garrafa para acarrear agua del manantial o la manguera que gotea, directamente relacionada al último instante de vida del padre, otro de los momentos inolvidables del libro. Las mismas asociaciones se establecen con lugares e inmuebles, una "topografía sentimental" que también podemos encontrar en Ware (Building Stories) o McGuire (la esquina del apartamento de Aqui como "máquina del tiempo" narrativa). La casa testimonia además costumbres españolas en vías de desaparición: la modesta segunda residencia construida por sus propietarios, tan pequeños como las propias casas, dice mucho entre líneas de la vida en este país durante

${ }^{4}$ Hay un libro que a mi juicio lo argumenta muy bien, por si acaso alguien no lo tiene en mente: La novela gráfica, de Santiago García (Astiberri, 2010), ahora en edición estadounidense (On the Graphic Novel, University Press of Mississippi, 2015, traducción al inglés de Bruce Campbell).

5 Jorge Carrión, en Rockdelux, op. cit. 
la segunda mitad del siglo xx. La otra cuestión final es el pudor que muestra Paco Roca como autor. Si en la narración de Los surcos del azar se introdujo con descaro como personaje en una entrevista con el veterano de La Nueve supuestamente real, precisamente porque era ficticia, en la autoficción de La Casa ha creado personajes interpuestos para hablar de su padre, de sí mismo y de su familia, precisamente porque lo que cuenta sobre ellos es verdad. La fotografía final de Paco Roca con su padre, ya fuera de la narración, aporta la prueba indicial de que, sí, todo está ficcionado pero todo es básicamente verdad.

Tal vez el mayor mérito de este cómic sea este. Que, siendo una historia tan personal, privada y en cierto modo "egoísta", su autor consiga hacer de ella un relato tan público, universal e interesante para los demás, tan lleno de verdad. Sus inspiradas viñetas nos traen antiguos recuerdos olvidados de la propia infancia, de tus padres cuando eran jóvenes, de los malos tragos en el hospital cuando les acompañas una y otra vez a los controles médicos cuando son ancianos, de las no siempre fáciles relaciones familiares. De, en fin, modos de vida de la generación de posguerra que literalmente levantó el país de las ruinas y procuró a sus hijos una infancia y educación mejores que las suyas. Hemos empezado este texto con las preguntas de Perec sobre lo trivial, lo cotidiano, lo evidente, lo común, lo ordinario, así que terminemos también con sus palabras. "Me importa poco que estas preguntas sean, aquí, fragmentarias, apenas indicativas de un método, como mucho de un proyecto. Me importa mucho que parezcan triviales e insignificantes: es precisamente lo que las hace tan esenciales o más que muchas otras a través de las cuales tratamos en vano de captar nuestra verdad" ${ }^{6}$

Pepo Pérez

Pepo Pérez (Málaga, 1969). Licenciado en Derecho y doctor en Bellas Artes por la Universidad de Málaga, donde es profesor, dibuja cómics y escribe sobre cómics. Visiting scholar en la School of Visual Arts de Nueva York (2013) y dibujante residente en La Maison des Auteurs de Angulema (2014), coautor junto a Santiago García de los cómics El vecino (2004-) y de numerosas bistorietas cortas para revistas como Nosotros Somos Los Muertos o El Manglar, como crítico ha escrito en Rockdelux, U, Volumen, El Periódico, Esquire, The Comics Grid, CuCo, Z, Revista de Libros o Mincho, y en los libros colectivos Del tebeo al manga. Una historia de los cómics, Supercómic $y$ On the Edge of the Panel. También en los blogs Con $\mathrm{C}$ de arte $y$ Es muy de cómic.

6 Perec, Lo infraordinario, op. cit., p. 24-25. 